\title{
Trading Blocs and Market Performance under Duopolistic Competition
}

\author{
R. Scott Hacker \\ Jönköping International Business School \\ Jönköping, Sweden \\ Qaizar Hussain \\ International Monetary Fund
}

\begin{abstract}
This paper uses a three-country duopoly model to examine the effects of lowered trade barriers when a new entrant joins a trading bloc. There are two firms - a small-country firm and a large-country firm within the bloc - and three markets two within and one (new entrant) outside the bloc. The results from trade bloc expansion vary for when marginal cost is falling with respect to output, but are clear when marginal cost is rising. In the latter case, profits improve more for the small-country firm than for the large-country firm. Consequences on prices, production, and trade are also considered.
\end{abstract}

- JEL Classifications: F15, F10, D43, D60

- Key words: Trading Blocs, Trade Barriers, Trade Expansion, Duopoly, Oligopoly, Tariffs, Preferential Trade Arrangement, Free Trade Area, Reciprocal Dumping

\footnotetext{
*Corresponding address: R. Scott Hacker, Jönköping International Business School P.O. Box 1026, SE 55111 Jönköping, Sweden, Tel: +46 361575 14, Fax: + 46361218 32, E-mail: Scott.Hacker@ihh. hj.se, Qaizar Hussain, International Monetary Fund, 700 19th Street, N.W., Washington D.C. 20431, U.S.A. Tel: +1-202-623-7334, Fax: +1-202-633-4422, E-mail: qhussain@imf.org (C2005-Center for International Economics, Sejong Institution, All Rights Reserved.
} 


\section{Introduction}

With the ever expanding and newly emerging economic unions of today, it is becoming even more important to analyze the implications of new union entrants on market performance. In recent years, there has been a great push toward regionalism as is evident from the successes of the EU, NAFTA, and APEC. Baldwin (1993) attributes this increased interest to a "domino theory" of regional trading blocs. ${ }^{1}$ A question arises as to how production, prices, and income of the existing members are affected as a result of the expansion of the bloc. In addition, does it matter if the existing member is large or small?

Current trade theory generally finds straightforward implications of cost or demand differences between countries when they are allowed to engage in free trade. The basis for these implications is almost always some type of comparative advantage, which is often associated with economies of scale. However, the literature is not clear about the implications of differences between countries when each of these countries simultaneously allows freer trade with other countries (as in the case of trade bloc expansion). Casella (1996) has formulated and tested a model of the relative impact of the entry of new members on large and small tradebloc members, using the expansion of the European Union as an example. She develops a model based on monopolistic competition with features such as economies of scale, Dixit-Stiglitz preferences, mobility of some types of labor within the trading bloc, and home-market advantage for domestic firms. ${ }^{2}$ Using this model, she finds that firms in small countries (e.g., Belgium and Ireland in the European Union) will enjoy a higher increase in welfare than firms in larger countries (e.g., Germany and France) when new entrants (e.g., Spain and Portugal) are permitted to join the trading bloc. The source of the greater increase in welfare for small countries lies in economies of scale. Due to their larger domestic markets, firms in large countries are able to produce at a lower average cost than firms in small countries. Lower-cost access to markets in countries formerly outside the trading bloc allows both small and large countries to take advantage of larger markets. However, the cost gains from expanding sales are greatest at lower levels

\footnotetext{
${ }^{1}$ This effect occurs when the political equilibrium (which balances anti- and pro-membership forces in a country) is altered by some event, contributing to a country's decision to join a regional trading bloc. As the disadvantages of non-membership to non-members increase, the momentum grows for them to join, resulting in a further enlargement of the bloc.
}

${ }^{2}$ Her model follows the tradition of Baldwin (1993) and Krugman (1991a, 1991b). 
of output. Therefore, firms in large countries (which already have large domestic markets) have less to gain than firms in small countries for the same expansion in sales.

An example of this logic is displayed in Figure 1. Before expanding the trade bloc, suppose that within a single industry, small-country firms produce at point $\mathrm{A}$ and large-country firms at point B along the common average cost curve, AC. If the firms from the two countries expand output by the same amount due to the expansion of a trade bloc, then the small-country firms would produce at point $\mathrm{A}^{\prime}$ and large-country firms would produce at point B'. The drop in average cost in this case is greater for the small-country firms, resulting in greater profit gains for these firms in relation to the large-country firms.

The policy implication of Casella's (1996) results, as noted by her, is that the potential loss of voting power that larger members of the European Union may experience because of expansion ${ }^{3}$ cannot be argued as a roughly equal exchange for their gaining more economically than small member countries. Large member countries (or their firms) might instead gain less than their small member-country counterparts.

Taking the case of Spain and Portugal's entry into the European Union in 1986, Casella obtains mixed results for her empirical tests. Her results are confirmed for France and the United Kingdom but not for Italy and Germany. ${ }^{4}$

Figure 1. Average Cost and Changes in Production Levels

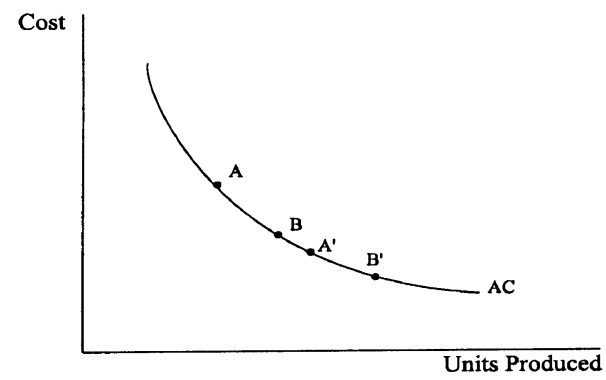

\footnotetext{
${ }^{3}$ Casella (1996) summarizes the work of Widgrén (1994a, 1994b), which deals with the impact of the expansion of the European Union on power shifts within the Union's Council of Ministers. She states, “... in general the power of the larger countries is reduced by the entry of new members: the admission of new countries increases the number of possible coalitions of smaller economies that can impose their preferences in matters subject to qualified majority" (p. 390).
}

${ }^{4}$ Her small country sample consists of Belgium, Denmark, Ireland, and the Netherlands. 
In this paper we use a three-country duopoly model to examine the effects of lowered trade barriers when a trading bloc admits new entrants. The three countries consist of a small country and a large country, both within the bloc, and an external country being considered for entry into the trade bloc. ${ }^{5}$ We examine an industry in which there are only two firms producing a single homogenous product: one in the small country and the other in the large country. Note that there is no firm producing the good in the external country. This assumption keeps the model relatively simple and is not unrealistic for many markets. For example, for Lithuania-one of the countries entering into the EU in 2004-the number of employees and the value of output for a number of industries at the four-digit ISIC classification level are noted as "nil or negligible" whereas these industries have non-negligible output among some current EU members. These industries include watches and clocks, motorcycles and motor vehicles (United Nations Industrial Development Organization, 2003). ${ }^{6}$

The paper considers how lower transaction costs on exports to the external country impact the quantities produced and sold, prices charged, and profits earned by each firm in each country. This model potentially has wide applications. For example, it could be used to predict the manner in which existing firms within trading blocs will be affected once new countries are allowed into the bloc at some point in the near future (for example, the inclusion of Central and East European countries into the European Union). Moreover, it can be used to empirically analyze the effects of previous expansions of preferential trading blocs in the world.

The model is in the theoretical tradition of the Brander (1981) reciprocal dumping model, which deals with a two-country duopoly (see also Brander and Krugman, 1983, or chapter 4 in Krugman, 1994). The reciprocal dumping model

\footnotetext{
${ }^{5}$ The size of the external country does not affect the results of our model.

${ }^{6}$ Once an external country joins a trade bloc, industrial production that did not exist in that country previously may very well continue not to exist. This can be due to lack of natural resources necessary to compete effectively, or due to strong external economies and dynamic increasing returns, giving firms existing inside the initial trade bloc such a cost advantage that considered startup firms in the external country due to trade bloc expansion would not survive. An example of industrial production that is not present in all members of a trade bloc is the motorcycle industry (4-digit industrial classification level), which has "nil or negligible" employees and output in Norway, but not in Sweden and Germany, fellow members in the European Economic Area (United Nations Industrial Development Organization, 2002). Moreover, at finer industrial classification levels than the four-digit one, one could expect to find more examples of industrial production that is not present in all member states of a trading bloc.
} 
indicates how intra-industry trade could come about without resorting to the assumption of product differentiation. This two-country duopoly model has been extended in other studies to a three-country oligopoly model with one or more firms in each of the countries. These three-country oligopoly models have been used to study incentives for bilateral trade liberalization and the effect of bilateral preferential free trade liberalization on incentives for multilateral liberalization (Krishna, 1998, Adriamananjara, 2000, Méndez Naya and Méndez Naya, 2001, and Haaparanta and Riipinen, 2001). All of the oligopoly models noted above both the earlier two-country and the later three-country versions - assume that there are identical constant marginal cost functions whereas our paper widens the analysis by considering falling and rising marginal cost situations in addition to constant marginal cost. Identical demand functions in the various countries is also a common assumption in the previous models that makes comparability to our model difficult. ${ }^{7}$ The spatial Nash equilibrium model of Hashimoto (1985) on the other hand is very broad, dealing with a general oligopoly over a finite number countries. The treatment of demand and marginal cost in the our model is a special case of Hashimoto's model, but while our model is more limited in generality, it does provide more depth for analyzing the issue of home-market size issues in the face of trade bloc expansion.

In terms of several issues studied, our model is most similar to Casella's (1996) model. However, our model deals with a different market structure than Casella's (duopoly rather than monopolistic competition). We find results that vary, depending most critically on how marginal cost changes with respect to output. Under some circumstances our results coincide with the same general idea as in Casella's paper, that small countries may have more to gain than large countries from trade bloc expansion due to small-country firms having more to gain from larger markets. However, falling average costs do not appear to drive those results in our model.

The next section presents the model and section III presents its equilibrium conditions. Section IV compares the price levels and quantities sold in each country and the quantities produced by each firm. Section V considers the effect on

\footnotetext{
${ }^{7}$ Haaparanta and Riipinen (2001) is a notable exception, and Krishna (1998) and Adriamananjara (2000) are partial exceptions: these two latter articles have some differences in demand available in their models, but when considering lower tariffs to a third country outside a preferential trade area, they maintain identical demands in the countries in the original preferential trade area. Markusen (1981) deals with the home-market size issue, but considers only a two-country situation.
} 
sales and prices from reducing tariffs on exports to the external country. Section VI discusses the effect of such tariff reductions on profits and consumer surplus. The last section concludes the paper.

\section{Assumptions for the Three-Country Duopoly Model}

We assume that there are three countries - a small country (country $S$ ), a large country (country $L$ ), and an external country (country $E$ ). We also assume that there are only two firms in the single industry we are considering-one in the small country (the " $S$-firm") and one in the large country (the " $L$-firm"). The two firms produce identical products, competing with each other in terms of quantity produced in all the three markets.

The term "country $C$ " is used when referring to any of the three countries, and the term " $F$-firm" is used when referring to either of the two firms. The single letter references noted so far $(S, L, E, C$, and $F)$ are used as prefixes as well as subscripts on variables.

The quantity produced by the $F$-firm for country $C$ is given by $Q_{F C}$, where $F \in\{S, L, T\}, C \in\{S, L, E, T\}$, and the subscript $T$ refers to total (i.e., $Q_{T C} \equiv$ $Q_{S C}+Q_{L C}$ and $\left.Q_{F T} \equiv Q_{F S}+Q_{F L}+Q_{F E}\right)$. For example, $Q_{L S}$ is the quantity sold by the $L$-firm to country $S, Q_{T S}$ is the total amount sold by both firms in country $S$, and $Q_{S T}$ is the total amount sold by the $S$-firm in all the three countries.

The two firms are assumed to have identical technologies available and face identical total cost functions of the form:

$$
t c_{F}=f c+0.5 m\left(Q_{F T}\right)^{2}+a_{m} Q_{F T},
$$

where $t c_{F}$ is the total production cost for the $F$-firm, $f c$ is fixed cost, $m$ and $a_{m}$ are constants, and $Q_{F T}$ is the total quantity sold by the $F$-firm. This functional form is chosen because it provides a marginal cost function that is linear with respect to $Q_{F T}$ (a simplifying assumption). ${ }^{8}$ The marginal production cost functions for the $S$ -

\footnotetext{
${ }^{8}$ This form may be regarded as an average of the linear approximations for the two firms' nonlinear marginal cost functions around their production points. However, if the linear approximations are very different, the results may be misleading.
} 
firm and $L$-firm are given by $2 \mathrm{a}$ and $2 \mathrm{~b}$ :

$$
\begin{aligned}
& M C_{S}=m\left(Q_{S T}\right)+a_{m}=m\left(Q_{S S}+Q_{S L}+Q_{S E}\right)+a_{m}, \\
& M C_{L}=m\left(Q_{L T}\right)+a_{m}=m\left(Q_{L S}+Q_{L L}+Q_{L E}\right)+a_{m},
\end{aligned}
$$

where $m$ represents the additional marginal cost of producing another unit by the $F$-firm. ${ }^{9}$

This paper treats factor markets as given and analyzes only the product market. Although fully endogenizing factor market variables would be desirable in this model, we believe that not doing so keeps the model tractable and does not change the results qualitatively. ${ }^{10}$

When a firm sells to an outside market, it accrues an additional transaction cost. Each unit exported between the small and large country costs an additional $t_{W}$ to the exporting firm (the $W$ subscript stands for "within" a union of the small country and the large country). Each unit exported to the country $E$ costs an additional $t_{E}$ to the exporting firm. Demand in each of the three countries is linear with the same price elasticity in each at every price. The inverse demand function in country $C$ is

$$
P_{C}=a_{d}-\left(1 / B_{C}\right) Q_{T C}
$$

where $a_{d}$ and $B_{C}$ are constants.

The demand function in each country must have the same price-axis intercept, $a_{d}$, in order to have the same price elasticity at every price. The higher demand resulting from a larger population is represented by a larger $B_{C}$, each unit of which represents a unit of population. The only difference in demand between the small country and the large country is $B_{S}<B_{L}$. This is notably different from the way varying demand is treated in other three-country reciprocal dumping models:

\footnotetext{
${ }^{9}$ The fact that marginal cost varies with output could be due to technological differences for different output levels.

${ }^{10}$ By contrast, Casella (1996) assumes a well-specified labor market with skilled labor (immobile within the bloc) and unskilled labor (fully mobile within the bloc). However, Casella's assumptions about labor mobility may not apply well to Europe. It is not clear whether unskilled workers in Europe are very mobile, considering the marked variations in languages and cultures. Also, some types of skilled laborers (such as doctors) may be more mobile than unskilled laborers, whereas other types of skilled laborers (such as factory workers with skills particular to one factory) are less mobile than unskilled laborers.
} 
Krishna (1998), Adriamananjara, 2000, and Haaparanta and Riipinen, 2001 have the intercept term, $a_{d}$, varying by country rather than the slope, $1 / B_{C}$. The impact of changing per capita income levels on demand in our model is not taken into account, again to maintain the tractability of the model.

\section{Equilibrium Conditions}

Our first goal is to find the Nash equilibrium, in which each firm is optimally setting its quantities in each market given what the other firm is selling in those markets. Each firm will want to set the marginal revenue from selling another good in a country equal to the marginal cost of selling to that country. Equations (4a)(4f) provide the set of implicit reaction functions. The left-hand side of each equation shows the marginal revenue for the $F$-firm selling in the country $C, M R_{F C}$, for each of the six cases $\left(M R_{S S}, M R_{S L}, M R_{S E}, M R_{L S}, M R_{L L}, M R_{L E}\right.$, in that order). The right-hand side of equations (4a)-(4f) includes the relevant marginal cost $\left(M C_{S}\right.$ or $\left.M C_{L}\right)$, plus any relevant transaction cost $\left(t_{W}\right.$ or $\left.t_{E}\right)$.

Therefore, we obtain the following implicit reaction functions:

$a_{d}-\left(2 Q_{S S}+Q_{L S}\right) / B_{S}=m\left(Q_{S S}+Q_{S L}+Q_{S E}\right)+a_{m} \quad$ (provides profit-maximizing $\left.Q_{S S}\right),(4 \mathrm{a})$

$a_{d}-\left(2 Q_{S L}+Q_{L L}\right) / B_{L}=m\left(Q_{S S}+Q_{S L}+Q_{S E}\right)+a_{m}+t_{W} \quad$ (provides profit-maximizing $\left.Q_{S L}\right),(4 \mathrm{~b})$

$a_{d}-\left(2 Q_{S E}+Q_{L E}\right) / B_{E}=m\left(Q_{S S}+Q_{S L}+Q_{S E}\right)+a_{m}+t_{E} \quad$ (provides profit-maximizing $\left.Q_{S E}\right),(4 \mathrm{c})$

$a_{d}-\left(Q_{S S}+2 Q_{L S}\right) / B_{S}=m\left(Q_{L S}+Q_{L L}+Q_{L E}\right)+a_{m}+t_{W} \quad$ (provides profit-maximizing $\left.Q_{L S}\right),(4 \mathrm{~d})$

$a_{d}-\left(Q_{S L}+2 Q_{L L}\right) / B_{L}=m\left(Q_{L S}+Q_{L L}+Q_{L E}\right)+a_{m} \quad$ (provides profit-maximizing $\left.Q_{L L}\right),(4 \mathrm{e})$

$a_{d}-\left(Q_{S E}+2 Q_{L E}\right) / B_{E}=m\left(Q_{L S}+Q_{L L}+Q_{L E}\right)+a_{m}+t_{E} \quad$ (provides profit-maximizing $\left.Q_{L E}\right)$. (4f)

The above implicit reaction functions (4a)-(4f), can be written explicitly and solved simultaneously. This results in a single Nash equilibrium set of six quantities (each defined as an equation based on the exogenous variables). Owing to the length of the resulting equations, these equations are relegated to Appendix I (equations A2.a-A2.f), along with the explicit reaction functions (equations A.1aA.1f). However, by taking derivatives and differences among the equations for Nash equilibrium quantities, we obtain some very clear characteristics about the Nash equilibrium solution. The conclusions we get are applicable only to internal solutions - that is, where the Nash equilibrium results in positive quantities sold by each firm at positive prices in each of the three markets. The conclusions naturally also apply only when the second-order conditions are met. These second-order 
conditions include the condition that $m>-2 / B_{C}$ for each country $C$ (the slope of marginal cost is greater than the slope of marginal revenue in each country, for profit maximization rather profit minimization).

In the next few sections we will discuss the results for falling, constant, and rising marginal cost. Falling marginal cost implies economies of scale, while constant or rising marginal cost may or may not be consistent with economies of scale. Those situations for which marginal cost is constant $(m=0)$ and those for which marginal cost is rising $(m>0)$ tend to have more conclusive results, so we will at points discuss these situations more in depth.

\section{Comparison of Quantities Produced and Sold, and Prices}

Let us consider the difference in total production between the firms. We find that

$$
Q_{L T}^{*}-Q_{S T}^{*}=t_{W}\left(B_{L}-B_{S}\right) /\left(m B_{T}+1\right)
$$

where $B_{T} \equiv B_{L}+B_{S}+B_{E}$ and the * superscript refers to equilibrium value; this notation will be used for this purpose throughout the paper.

It is also possible to compare the quantities sold by each firm in each country. We find the following:

$$
\begin{aligned}
& Q_{S S}^{*}-Q_{L S}^{*}=t_{W}\left(2 m B_{L}+m B_{E}+1\right) B_{S} /\left(m B_{T}+1\right), \\
& Q_{L L}^{*}-Q_{S L}^{*}=t_{W}\left(2 m B_{S}+m B_{E}+1\right) B_{L} /\left(m B_{T}+1\right), \\
& Q_{S E}^{*}-Q_{L E}^{*}=t_{W}\left(m B_{L}-m B_{S}\right) B_{E} /\left(m B_{T}+1\right) .
\end{aligned}
$$

Note that according to equations (5) through (8) if the transaction cost between the small country and large country, $t_{W}$, were zero, then both firms would sell exactly the same amount in each market and in total. This result occurs because the two firms would then face identical market conditions.

Table 1 summarizes the signs of equations (5) through (8) for various levels of marginal cost slope in relation to $B_{T}$ for positive transaction costs. The three categories of $m$ with respect to $B_{T}$ when $m<-1 / B_{T}$ have no distinguishing importance in this table but are provided for comparative purposes to later tables. One might suspect that some of these categories are irrelevant due to failing 
Table 1. Signs of Quantity Comparisons Under Alternative Assumptions for Slope of Marginal Cost $(m)$ in Relation to Sum of Slopes of Demand Curves $\left(B_{T}\right)^{\mathrm{a}}$

\begin{tabular}{|c|c|c|c|c|c|c|}
\hline & $m<-3 / B_{T}$ & $-3 / B_{T} \leq m<-2.5 / B_{T}$ & $-2.5 / B_{T} \leq m<-1 / B_{T}$ & $-1 / B_{T}<m<0$ & $m=0$ & $m>0$ \\
\hline$Q_{L T}^{*}-Q_{S T}^{*}$ & - & - & - & + & + & + \\
\hline$Q_{S S}^{*}-Q_{L S}^{*}$ & + & + & + & b & + & + \\
\hline$Q_{L L}^{*}-Q_{S L}^{*}$ & $\mathrm{c}$ & $\mathrm{c}$ & c & d & + & + \\
\hline$Q_{S E}^{*}-Q_{L E}^{*}$ & + & + & + & - & 0 & + \\
\hline
\end{tabular}

a: Note: All signs are undefined for $m=-1 / B_{T}$.

b: - if $m<-1 /\left(2 B_{L}+B_{E}\right), 0$ if $m=-1 /\left(2 B_{L}+B_{E}\right),+$ if $m>-1 /\left(2 B_{L}+B_{E}\right)$

c: + if $m<-1 /\left(2 B_{S}+B_{E}\right), 0$ if $m=-1 /\left(2 B_{S}+B_{E}\right),-$ if $m>-1 /\left(2 B_{S}+B_{E}\right)$

$\mathrm{d}:-$ if $m<-1 /\left(2 B_{S}+B_{E}\right), 0$ if $m=-1 /\left(2 B_{S}+B_{E}\right),+$ if $m>-1 /\left(2 B_{S}+B_{E}\right)$

second-order conditions or providing unstable results. However numerical examples have indicated none of the categories consistently fail second-order or stability conditions.

We see that in cases of rising or constant marginal cost $(\mathrm{m}>0$ or $\mathrm{m}=0$, respectively) that the $L$-firm sells more than the $S$-firm and each firm will produce more for its domestic market than the foreign firm. The $L$-firm sells more overall because it faces a larger domestic market, which is somewhat protected due to the positive transaction cost on trade between the countries. In the simplest case, of constant marginal cost, the firm with the lower transaction cost has the advantage in any particular market. That is why each firm sells more in its domestic market than the other firm and why the two firms sell the same amount in the external country, where they have identical transaction costs. With constant marginal cost, decisions on production for sales in each market can be made independently of information on what is happening in other markets. This same conclusion was found in Krishna (1998).

When marginal cost is rising, this basic intuition remains the same, except the higher output the $L$-firm has because of its larger domestic market results in it having higher marginal cost than the $S$-firm, putting the $L$-firm at a disadvantage in the external market with respect to the $S$-firm. Therefore, the $L$-firm sells less to the external market than the $S$-firm. If marginal cost is moderately declining, $-1 / B_{T}$ $<m<0$, the $L$-firm sells more than the $S$-firm to country $E$. This happens because the $L$-firm's greater total production now gives it a cost advantage in the external market with respect to the $S$-firm. If marginal cost is sharply declining $\left(m<-1 / B_{T}\right)$, we get some results that are not easily explained: the $S$-firm produces more than the $L$-firm and again sells more in its domestic market and in the external market 
than the $L$-firm.

By plugging the equilibrium quantities into the inverse demand relation, (3), for each country, and then finding the difference in prices between countries, we arrive at simple equilibrium relationships in prices (see Appendix I):

$$
\begin{aligned}
& P_{L}^{*}=P_{S}^{*}, \\
& P_{E}^{*}-P_{L}^{*}=P_{E}^{*}-P_{S}^{*}=2 t_{E} / 3-t_{W} / 3 .
\end{aligned}
$$

Owing to the identical price elasticity of demand in the small and large countries, identical prices are charged in both markets, just as we would expect if a monopoly with no transaction cost were price discriminating between these markets. Also, since identical prices are charged in both markets, there must be greater sales in the large country due to its higher population. In equation (10) we see that as the transaction cost on trade with the external country increases, the price level in that country increases compared to the price level in the other countries as we would expect. With higher transaction cost on trade between the small and large countries however, one would expect in most circumstances for there to be less sales and higher prices in these countries and more sales and lower prices in the external country, all else equal. This is reflected in equation (10) with the negative effect of increases in $t_{W}$ on $P_{E}^{*}-P_{L}^{*}$ and $P_{E}^{*}-P_{S}^{*}$. From equation (10) we also find that under the special case in which the transaction cost of exporting to the external country is the same as the transaction cost between the large and small countries, the price would be higher in the external country than in the other two countries. This is likely due to the fact that not all sales in the small and large countries involve a transaction cost (some sales are by domestic firms), whereas all sales in the external country must involve a transaction cost.

\section{Effect of Change in Tariffs on Sales and Prices}

With the help of this model, we can examine the impact of changes in transaction costs on imports into the external country on each firm's profits and sales in each market. We can then say something about what happens when, for instance, a new member country is allowed into a preferential trade arrangement.

Taking the first derivative of the Nash equilibrium quantities found in Appendix I with respect to $t_{E}$, we find the following relations: 


$$
\begin{aligned}
& \frac{d Q_{S S}^{*}}{d t_{E}}=\frac{d Q_{L S}^{*}}{d t_{E}}=\frac{B_{S}\left[m^{2} B_{E} B_{T}+m B_{E}\right]}{D}, \\
& \frac{d Q_{S L}^{*}}{d t_{E}}=\frac{d Q_{L L}^{*}}{d t_{E}}=\frac{B_{L}\left[m^{2} B_{E} B_{T}+m B_{E}\right]}{D}, \\
& \frac{d Q_{S E}^{*}}{d t_{E}}=\frac{d Q_{L E}^{*}}{d t_{E}}= \\
& \frac{-B_{E}\left[m^{2}\left(B_{S} B_{E}+2 B_{S} B_{L}+B_{L} B_{E}+B_{S}^{2}+B_{L}^{2}\right)+m\left(4 B_{S}+4 B_{L}+3 B_{E}\right)+3\right]}{D}, \\
& \frac{d Q_{S T}^{*}}{d t_{E}}=\frac{d Q_{L T}^{*}}{d t_{E}}=\frac{d Q_{S S}^{*}}{d t_{E}}+\frac{d Q_{S L}^{*}}{d t_{E}}+\frac{d Q_{S E}^{*}}{d t_{E}}=\frac{-3 B_{E}\left[m B_{T}+1\right]}{D}
\end{aligned}
$$

where $D \equiv 3\left(m B_{T}+3\right)\left(m B_{T}+1\right)$.

Table 2 summarizes the information we can obtain from equations (11) through

\begin{tabular}{|c|c|c|c|c|c|c|}
\hline Change in .. & $m<-3 / B_{T}$ & $-3 / B_{T}<m<-2.5 / B_{T}$ & $-2.5 / B_{T} \leq m<-1 / B_{T}$ & $-1 / B_{T}<m<0$ & $m=0$ & $m>0$ \\
\hline $\begin{array}{l}Q_{F E}^{*} \\
\mathrm{~F} \in\{\mathrm{S}, \mathrm{L}\}\end{array}$ & b & + & + & + & + & + \\
\hline $\begin{array}{l}Q_{F T}^{*} \\
\mathrm{~F} \in\{\mathrm{S}, \mathrm{L}\}\end{array}$ & - & + & + & + & + & + \\
\hline $\begin{array}{l}Q_{F C}^{*} \\
F \in\{S, L\}, \\
\mathrm{C} \in\{\mathrm{S}, \mathrm{L}\}\end{array}$ & - & + & + & + & 0 & - \\
\hline $\begin{array}{l}P_{C}^{*} \\
\mathrm{C} \in\{\mathrm{S}, \mathrm{L}\}\end{array}$ & + & - & - & - & 0 & + \\
\hline $\begin{array}{l}Q_{F L}^{*}-Q_{F S}^{*} \\
F \in\{S, L\}\end{array}$ & - & + & + & + & 0 & - \\
\hline
\end{tabular}
(14) for various levels of marginal cost slope in relation to $B_{T}{ }^{11}$ Here we provide

Table 2. Signs of Quantity and Price Changes Due to a Marginal Tariff Reduction with the External Country, by Relation of Marginal Cost Slope $(m)$ to Sum of Slopes of Demand Curves $\left(B_{T}\right)^{\mathrm{a}}$

a: These are the signs of the negative of the derivative of the given row variable with respect to $t_{E}$. All signs are undefined for $m=-1 / B_{T}$ and $m=-3 / B_{T}$.

b: - if $m<-3 /\left(B_{S}+B_{L}\right), 0$ if $m=-3 /\left(B_{S}+B_{L}\right),+$ if $m>-3 /\left(B_{S}+B_{L}\right)$

\footnotetext{
${ }^{11}$ The signs in this table are determined in a relatively straightforward manner from equations (11)-(14), but the following knowledge is helpful. Knowing that the function $f(m)=m^{2} B_{E}\left(B_{S}+B_{L}+B_{E}\right)+m B_{E}$ is a parabola in which $f(m)$ is negative between the points $m=0$ and $m=-1 / B_{T}$ helps in determining the sign of the numerator in (11) and (12). The fact that the function $g(m)=m^{2}\left(B_{S} B_{E}+2 B_{S} B_{L}+B_{L} B_{E}+B_{S}^{2}\right.$ $\left.+B_{L}^{2}\right)+m\left(4 B_{S}+4 B_{L}+3 B_{E}\right)+3$ is a parabola in which $g(m)$ is negative between the points $m=-1$ / $B_{T}$ and $m=-3 /\left(B_{S}+B_{L}\right)$ is useful in determining the sign of the numerator in (13).
} 
results on changes in variables with respect to a small reduction in $t_{E}$ (representative of trade bloc expansion) by presenting the sign of the negative of derivatives for the noted variables with respect to $t_{E}$. The first row presents the signs for $-d Q_{F E}^{*} / d t_{E}$, for example. We do this so that the presented signs represent what happens when there is a decrease in $t_{E}$, as would be the case when there is a trade bloc expansion.

We see from the first row of this table that, as we would expect, a drop in the transaction cost for sales in the external country leads to more sales in that country, and that induces the firms to produce more overall as shown in the second row (exceptions to these statements occur when marginal cost is very negatively related to output, as seen in the first column). The third row of the table reflects sales changes in the small and large country markets as a result of the total output increase. There is no change in those markets if marginal cost is unaffected by output (equilibriums in the three markets are independent of each other in this case), but sales decrease in those markets if marginal cost rises with the additional output and they increase in those markets if marginal cost decreases with the additional output. This matches economic intuition: higher cost to provide products to a market leads to less amount produced for that market.

The fourth row in the table reflects the necessary price changes in the small and large country markets, which due to the law of demand must be inversely related to the sales changes in those markets noted in the third row. Prices must change by the same amount in both the small and large countries, as the price level must be the same in both countries before and after the $t_{E}$ change (see equation (9)) due to the identical price elasticity of demand. With the price increasing (decreasing) by the same amount in each of the two countries, it must be the case that the quantity sold by each firm to the large country decreases (increases) more than the quantity sold to in the small country (indicated in the last row of the table). This result is true because both countries face the same percent change in price resulting in the same percent fall in quantity sold, and this requires a greater absolute change in quantity sold in the large country than in the small country.

From equation (10), we can also determine how much the price differential between the external country and the other countries will change when $t_{E}$ changes. In particular,

$$
\frac{d\left(P_{E}^{*}-P_{L}^{*}\right)}{d t_{E}}=\frac{d\left(P_{E}^{*}-P_{S}^{*}\right)}{d t_{E}}=2 / 3 .
$$


Therefore when $t_{E}$ decreases, the difference between the external country price and the price in the other countries will be reduced.

How market shares of the two firms in each market change in the case of rising marginal cost can be discussed with the help of graphical analysis. Figures $2 \mathrm{a}, 2 \mathrm{~b}$, and $2 \mathrm{c}$ are used for this purpose. These figures show how each firm's sales in each country vary with $t_{E}$, with a positive relation in the small and large countries and a negative one in the external country, as is consistent with equations (11)-(13) and rows 1 and 3 in Table 2. Also to be consistent with these equations, the two lines in each graph are shown as parallel, indicating the effect of $t_{E}$ changes on the sales in any particular market is identical for both firms and invariant with the level of $t_{E}$. To match the information from equations (6)-(8), the $S$-firm sells more than the $L$ firm in the small country and the external country, and the $L$-firm sells more than the $S$-firm in the large country. Note that the lines in these figures and the equations upon which they are based are only valid in the range of $t_{E}<t_{E}^{M}$, where $t_{E}^{M}$ is the maximum $t_{E}$ for which the large-country firm would sell to the external country (if $t_{E} \geq t_{E}^{M}$, we would not have an internal solution). With the equal increases or decreases by both firms in the markets in response to $t_{E}$ falling, changes in market shares will result. In response to a reduction in the external country tariff, each firm will gain market share in its own domestic market, and the large country will gain market share within the external country. This can be seen in figures $2 \mathrm{a}, 2 \mathrm{~b}$, and $2 \mathrm{c}$.

It is useful to consider what could happen to our model's results if the lowering of trade barriers induced the entry of a firm in the industry in the entrant country. One could expect that this would make an increase in sales in the original member countries more likely, putting more downward pressure on prices and making the consumers in those countries better off. Output of the small and large country firms

Figure 2a. Quantities Sold in Small Country, $m>0$

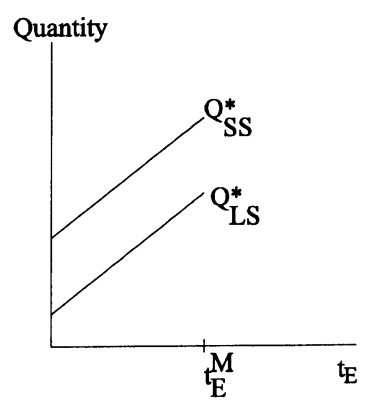

Figure 2b. Quantities Sold in Large Country, $m>0$

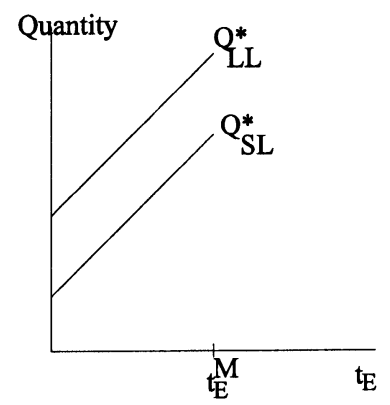

Figure 2c. Quantities Sold in External Country, $m>0$

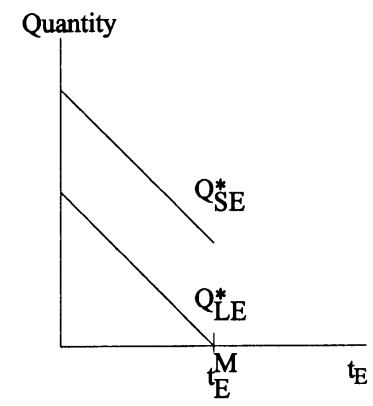


would be lower than otherwise. Due to the identical demand elasticities in the original trade bloc countries and the identical transaction cost for trade between the entering country and the original trade bloc members, prices would fall in the two original trade bloc countries by the same amount. The impact on profits for the original firms as a result of trade bloc expansion, described in detail in the next section for our duopoly model with no firm entry, would be made more unclear if firm entry in the entrant country were allowed, depending on the strength of the newly established firm.

\section{Effect of a Change in Tariffs on Profits and Consumer Surplus}

One concern of our paper is whether a drop in tariffs on the external country's imports improves the well-being of those in the small and large countries, the original trade-bloc members. The answer to this question may naturally be anticipated to be different for different groups in society. We focus here on the impact of trade bloc expansion on original trade bloc residents as owners of the firms and as consumers of the products of the firms.

The question of how residents are affected by the trade bloc expansion as owners of the firms is the more difficult question. First, we would like to determine whether profits of the two firms rise or fall as a result of trade bloc expansion. Second, we would like to see whether residents in one country benefit more (or lose less) than those in another from profit changes in these firms. If residents in both the small country and the large country are identically diversified in their portfolios across these two firms, then all residents across both countries are of course affected identically by profit changes. In practice, however, residents often tend to be more heavily invested in domestic firms. We consider the extreme case where firms are invested in only by domestic residents, so we are simply interested in whether there are more profit gains to one firm than to the other as a result of trade bloc expansion.

The profits for the small and large country firms, $\pi_{S}$ and $\pi_{L}$ respectively, may be written down as explicit functions, and derivatives of these function respect to $t_{E}$ may be found, as is done in Appendix II. Unfortunately, that exercise does not lead us to a conclusive statement on whether profits will rise or not for each of the firms as a result of trade bloc expansion. Nevertheless, we believe the profits of the firms should rise under $m \geq 0$ due to the following thought experiment. 
Consider two situations of this model, $x$ and $z$. Situation $x$ and $z$ are identical except situation $z$ has a lower $t_{E}$. Letting $Q_{F C}^{i}$ be the equilibrium quantity sold by firm $F$ in country $C$ under situation $i$ (which may be $x$ or $z$ at this point), we have

$$
Q_{F T}^{x}-Q_{F T}^{z}=\left(Q_{F S}^{x}-Q_{F S}^{z}\right)+\left(Q_{F L}^{x}-Q_{F L}^{z}\right)+\left(Q_{F E}^{x}-Q_{F E}^{z}\right)
$$

If $m \geq 0$, both sides of the equality should be negative, and the last parentheses term should be negative. If $m>0$, the first and second parentheses term on the right side should be positive, but they are zero if $m=0$.

Now suppose we consider a third situation, $y$, in which the firms have the lower $t_{E}$ of situation $z$, but are mandated to set $Q_{F S}^{y}=Q_{F S}^{x}$ and $Q_{F L}^{y}=Q_{F L}^{x}$ while maintaining $Q_{F T}^{y}=Q_{F T}^{z}$. If $m=0$, situations $y$ and $z$ have identical outcomes, but with $m>0$ the firms in situation $y$ are forced into each having lower profits than in situation $z$, since the firms must sell more in the small and large countries, and less in the external country than is profit maximizing. The marginal cost is the same in situation $y$ and $z$, but in situation $y$ with $m>0$ marginal revenue net of transaction cost is higher than marginal cost for output headed to the external country.

Comparing situations $x$ and $y$, we find they are identical except $Q_{F E}^{x}<Q_{F E}^{y}$ (leading to $Q_{F T}^{x}<Q_{F T}^{y}$ ) and $t_{E}$ is higher. Each firm in situation $x$ sells less to the external market, which in situation $y$ was already profitable for additional units sold, and for what output under situation $x$ is still sold to the external country is subject to a higher $t_{E}$. The additional cost through a higher $t_{E}$ is offset somewhat by a higher price for the product in the external country, but we do not expect the higher price to more than offset the higher $t_{E}$, as that would imply a negative tax burden for the firms. Therefore, we expect each firm's profits in situation $x$ to be lower than that in $y$, which have already be demonstrated to be lower (under $m>0$ ) or the same (under $m=0$ ) as those in situation $z$. Thus lower $t_{E}$ should increase profits to each firm under constant or rising marginal costs.

Considering the how the profit changes in one firm compare to those in the other, we can use the following result based on an equation derived in Appendix II (both sides of equation (A11) in that appendix are multiplied by -1 ):

$$
-\frac{d\left(\pi_{L}^{*}-\pi_{S}^{*}\right)}{d t_{E}}=\frac{(R-1) B_{L} B_{E} m t_{w}\left[(2 / 3)+1 /\left(m B_{E}+(1+R) m B_{L}+1\right)\right]}{\left(m B_{E}+(1+R) m B_{L}+3\right)},
$$

where $R=B_{S} / B_{L}, 0<R<1$. In Table 3 we present the signs for equation (17) for 
Table 3. Signs of Changes in Profits and Consumer Surplus Differences Due to a Marginal Tariff Reduction with the External Country, by Relation of Marginal Cost Slope $(m)$ to Sum of Slopes of Demand Curves $\left(B_{T}\right)^{\mathrm{a}}$

\begin{tabular}{lcccccc}
\hline Change in $\ldots$ & $m<-3 / B_{T}$ & $-3 / B_{T}<m<-2.5 / B_{T}$ & $-2.5 / B_{T} \leq m<-1 / B_{T}$ & $-1 / B_{T}<m<0$ & $m=0$ & $m>0$ \\
\hline$\pi_{L}^{*}-\pi_{S}^{*}$ & - & - & $+^{\mathrm{b}}$ & + & 0 & - \\
$\Psi_{C}$ & & & & & & \\
$C \in\{S, L\}$ & - & + & + & + & 0 & - \\
\hline
\end{tabular}

a: These are the signs of the negative of the derivative of the given row variable with respect to $t_{E}$. All signs are undefined for $m=-1 / B_{T}$ and $m=-3 / B_{T}$.

b: indeterminate at $m=-2.5 / B_{T}$

various levels of $m^{12}$

The question of how consumers are affected by trade bloc expansion is easy to deal with if we are just interested in if the effect is positive or negative. Country $C$ 's consumer surplus, $\Psi_{C}, C \in\{S, L\}$, is inversely related to the price faced by consumers. Therefore, the signs on $-d \Psi_{C} / d t_{E}$ for the various levels of $m$, given in Table 3, are simply the opposite of those on $-d P_{C}^{*} / d t_{E}$ given in Table 2 . Consumers are affected in the same way regardless of whether they live in the small country or in the large country since prices are the same in both according to equation (9).

We see a variety of things from Table 3 . For falling marginal cost the situation is rather complicated. For a wide range of negative $m$ values $\left(-3 / B_{T}<m<0\right)$ consumers in both the small country and the large country are better off as firms decrease prices in response to lower marginal costs. The magnitudes of these consumer surplus changes are larger in the larger country due to its size, but they are the same in the two countries on a per capita basis. For not-so-negative values of $m$-negative values higher than $-2.5 / B_{T}$ - profits increase more (or decrease less) for the large-country firm in response to trade bloc expansion, but the opposite is true for values of $m$ lower than $-2.5 / B_{T}$.

If $m=0$, trade bloc expansion only affects activities in the external market, as it will be dealt with independently from the small and large country markets under these circumstances. Therefore, consumers in the original trade bloc countries are unaffected. As noted previously, we do expect profits to rise under these circumstances for both firms, and the rise in profits should be the same for each

\footnotetext{
${ }^{12}$ The fact that $2 / 3+1 /\left(m B_{T}+1\right)$ is negative, if and only if $-2.5 / B_{T}<m<-1 / B_{T}$ is useful in determining the sign of the numerator in (17).
} 
firm as they would be in identical circumstances with respect to the external market. If $m>0$, profits are expected to rise for both firms in reaction to $t_{E}$ falling, but according to table 3 they should rise more for the small-country firm. In percentage terms, we expect this to be true also, as the higher costs faced by the small-country firm-arising from its less favorable position of a smaller zerotransactions-cost (domestic) market - means the small country firm starts with a smaller profit base than the large-country firm. With domestic residents investing more heavily in domestic firms, we see trade bloc expansion under these circumstances helping the small country more than the large country (or not hurting the small country as much as the large one). The parenthetical statement in the last sentence is included since consumer surplus also falls with trade bloc expansion when $m>0$ (falling identically in both countries in per capita terms). This fall in consumer surplus is due to higher prices in the original trade bloc countries as output for sales in those countries is cut back to expand exports to the external country. Possibly both countries are made worse off with a lower $t_{E}$ because of the higher prices, but if that is true the small country's situation change is not as bad as the large country's since the small-country firm's profits are increasing more than those for the large-country's firm.

In our model, the source of the advantage to small countries derived from sales expansion under $m>0$ is different from that in Casella's model. In our model, rising marginal costs and identical price elasticities of demand across countries, rather than falling average costs, drive the results. The law of demand and the existence of market power mean that the two firms in the model face falling prices as they expand output in any market. However, the price level must be lowered more quickly in a small population market than in a large population market to increase sales by one unit. All else being equal, a firm with a larger market is thus willing to sell more. Since a firm from a small country faces a smaller domestic market than a firm from a large country, the small-country firm will be willing to produce and sell less in general. However, the small-country firm has an advantage in selling to the external country under such circumstances, because this firm will have lower marginal costs due to lower output. This advantage results in the smallcountry firm generally selling more to the external country than the large-country firm. When the transaction costs of selling to the external country are lowered (owing to its entry into the trade bloc, or for any other reason), the profits of the small-country firm will increase more than those of the large-country firm for two reasons. First, the small-country firm will have a larger volume of exports for 
which the transaction costs will be lowered. Second, the small-country firm will increase its exports to the external country through trade diversion more than the large-country firm will, so the small-country firm saves more on the transaction costs associated with the previous sales of those diverted exports.

\section{Conclusions}

This paper has analyzed how an industry's activities and outcomes are affected by lowered transaction costs on the imports of new entrants wishing to join a preferential trading bloc. We have used a three-country duopoly model to examine the effects of a new entrant on the quantities produced and sold, prices charged, and profits earned by firms already within the bloc. This topic is of great significance as new countries are allowed into the numerous trading blocs and economic unions in existence all over the world.

We find our results are sensitive to how marginal cost changes with respect to changes in output, and categorize the results accordingly. When marginal cost is constant or rising with respect to output, our results are more conclusive than when marginal cost is falling. If marginal cost is constant, both firms in our model simply increase their sales to the new entrant country, and these sales are equal across firms before and after trade bloc expansion. Profits rise equally for both firms, but they are higher in percentage terms for the small firm. Sales in the original bloc countries do not change, so consumers in these countries are not affected.

With rising marginal cost, the results from trade bloc expansion are similar to that with constant marginal cost, except the firms reduce their sales in the original bloc countries, resulting in higher prices and lower consumer surpluses in those countries, and in higher market shares for domestic firms in these countries. In this case the profits of both firms rise, but more greatly for the small firm, both in absolute and in percentage terms. Again, both firms increase sales equally to the new-entrant country, but the small-country firm loses in market share there since it initially should have more sales to the new-entrant country.

With falling marginal cost different conclusions arise depending on how sharply marginal cost is falling. An attempt to categorize conclusions on how quickly marginal cost falls has been made. Sometimes these results can be counterintuitive, such as reduced trade barriers leading to less production.

Our results demonstrate that even with our simple model, it is difficult to be conclusive about what happens in a duopolistic market with trade bloc expansion. 
Nevertheless, with some information about the nature of marginal costs in an industry with few firms, we think our results may be useful for determining the differential impact of trade bloc expansion on current trade bloc members.

\section{Acknowledgements}

The authors are grateful to Hassan Al-Atrash, Börje Johansson, Ashok Bardhan, Thomas Dorsey, Mohsin Khan, Ernesto Stein, Timo Valila, Clas Wihlborg, and Philip Wong, for valuable comments. All remaining errors are the responsibility of the authors.

Received 21 January 2003, Accepted 23 April 2004

\section{References}

Adriamananjara, S. (2000). Regionalism and Incentives for Multilateralism, Journal of Economic Integration, 15: 1-18.

Baldwin, R. (1993) A Domino Theory of Regionalism, NBER Paper No. 4465, National Bureau of Economic Research, Cambridge, Massachusetts

Brander, J. (1981) Intra-industry Trade in Identical Commodities, Journal of International Economics, 11, 1-14

Brander, J., Krugman, P. (1983) A "Reciprocal Dumping Model" of International Trade, Journal of International Economics, 15, 313-321

Casella, A. (1996) Large Countries, Small Countries and the Enlargement of Trade Blocs, European Economic Review, 40, 389-415

Haaparanta, P., Riipinen, T. (2001) Regionalism and International Environmental Agreements. Working paper, Helsinki School of Economics.

Hashimoto, H. (1985) "A Spatial Nash Equilibrium Model," in Spatial Price Equilibrium: Advances in Theory, Computation and Application. Proceedings, Denver, 1984 (Ed.) Harker, P., in Lecture Notes in Economics and Mathematical Systems (Ed.) Beckman,

M., Krelle, W., Vol. 249, Springer-Verlag, Berlin and New York, pp. 20-40, International Monetary Fund, International Financial Statistics, various issues. International Monetary Fund, Balance of Payments Statistics, various issues.

Krishna, P. (1998) Regionalism and Multilateralism: A Political Economy Approach, The Quarterly Journal of Economics, February, 227-251.

Krugman, P. (1991a) Increasing Returns and Economic Geography, Journal of Political Economy 99, 483-499

Krugman, P. (1991b) Geography and Trade, MIT Press, Cambridge, Massachusetts Krugman, P. (1994) Rethinking International Trade, MIT Press, Cambridge, Massachusetts 
Markusen, J. (1981) Trade and the Gains from Trade with Imperfect Competition, Journal of International Economics 11: 531-551.

Méndez Naya, J., Méndez Naya L. (2001) Subsidios a la Producción y Efectos Derivados de la Formación de una Unión Aduanera, Estudios de Economia. 28, 249-265.

Varian, H. (1984) Microeconomic Analysis, $2^{\text {nd }}$ ed., W. W. Norton \& Company, New York United Nations Industrial Development Organization (2002) International Yearbook of Industrial Statistics 2002.

United Nations Industrial Development Organization (2003) International Yearbook of Industrial Statistics 2003.

Widgrén, M. (1994a) "Voting Power in the EC Decision Making and the Consequences of Two Different Enlargements," European Economic Review 38, 1153-1170

Widgrén, M. (1994b) The Relation Between Voting Power and Policy Impact in the European Union, CEPR Discussion Paper No. 1033, Center for Economic Policy Research, London 


\section{Appendix I: The Nash Equilibrium}

The implicit reaction functions, (4a)-(4f), can be written explicitly as follows:

$$
\begin{aligned}
& Q_{S S}=\left(B_{S}\left(a_{d}-a_{m}\right)-Q_{L S}-m B_{S}\left(Q_{S L}+Q_{S E}\right)\right) /\left(m B_{S}+2\right) \\
& Q_{S L}=\left(B_{L}\left(a_{d}-a_{m}\right)-Q_{L L}-m B_{L}\left(Q_{S S}+Q_{S E}\right)-B_{L} t_{W}\right) /\left(m B_{L}+2\right), \\
& Q_{S E}=\left(B_{E}\left(a_{d}-a_{m}\right)-Q_{L E}-m B_{E}\left(Q_{S S}+Q_{S L}\right)-B_{E} t_{E}\right) /\left(m B_{E}+2\right), \\
& Q_{L S}=\left(B_{S}\left(a_{d}-a_{m}\right)-Q_{S S}-m B_{S}\left(Q_{L L}+Q_{L E}\right)-B_{S} t_{W}\right) /\left(m B_{S}+2\right), \\
& Q_{L L}=\left(B_{L}\left(a_{d}-a_{m}\right)-Q_{S L}-m B_{L}\left(Q_{L S}+Q_{L E}\right)\right) /\left(m B_{L}+2\right), \\
& Q_{L E}=\left(B_{E}\left(a_{d}-a_{m}\right)-Q_{S E}-m B_{E}\left(Q_{L S}+Q_{L E}\right)-B_{E} t_{E}\right) /\left(m B_{E}+2\right) .
\end{aligned}
$$

The equilibrium quantities resulting from solving (A1.a) - (A1.f) simultaneously are given below. ${ }^{13}$ Letting $D \equiv 3\left(m\left(B_{S}+B_{L}+B_{E}\right)+3\right)\left(m\left(B_{S}+B_{L}+B_{E}\right)+1\right)$ and $X \equiv 3 a_{d}\left(m B_{S}+m B_{L}+m B_{E}+1\right)$, the Nash equilibrium outcomes for the quantities are

$$
\begin{aligned}
& Q_{S S}^{*}=\left(B_{S} / D\right)\left[X+t_{E}\left(m^{2} B_{E}\left(B_{S}+B_{L}+B_{E}\right)+m B_{E}\right)\right. \\
& \left.+t_{W}\left(m^{2}\left(4 B_{L} B_{E}+3 B_{L} B_{S}+3 B_{L}^{2}+B_{E}^{2}+B_{S} B_{E}\right)+m\left(9 B_{L}+4 B_{E}\right)+3\right)\right] \\
& Q_{S L}^{*}=\left(B_{L} / D\right)\left[X+t_{E}\left(m^{2} B_{E}\left(B_{S}+B_{L}+B_{E}\right)+m B_{E}\right)-t_{W}\left(m ^ { 2 } \left(2 B_{L} B_{E}+3 B_{L} B_{S}\right.\right.\right. \\
& \left.\left.\left.+3 B_{L}^{2}+2 B_{E}^{2}+5 B_{S} B_{E}\right)+m\left(12 B_{S}+3 B_{L}+8 B_{E}\right)+6\right)\right] \\
& Q_{S E}^{*}=\left(B_{E} / D\right)\left[X-t_{E}\left(m^{2}\left(B_{S} B_{E}+2 B_{S} B_{L}+B_{L} B_{E}+B_{S}^{2}+B_{L}^{2}\right)\right.\right. \\
& \left.+m\left(4 B_{S}+4 B_{L}+3 B_{E}\right)+3\right)+t_{W}\left(m^{2}\left(2 B_{L} B_{E}+B_{L} B_{S}+2 B_{L}^{2}-B_{S} B_{E}-B_{S}^{2}\right)\right. \\
& \left.\left.+m\left(5 B_{L}-4 B_{S}\right)\right)\right] \\
& Q_{L S}^{*}=\left(B_{S} / D\right)\left[X+t_{E}\left(m^{2} B_{E}\left(B_{S}+B_{L}+B_{E}\right)+m B_{E}\right)-t_{W}\left(m ^ { 2 } \left(2 B_{S} B_{E}+3 B_{L} B_{S}\right.\right.\right. \\
& \left.\left.\left.+3 B_{L}^{2}+2 B_{E}^{2}+5 B_{L} B_{E}\right)+m\left(12 B_{L}+3 B_{S}+8 B_{E}\right)+6\right)\right] \\
& Q_{L L}^{*}=\left(B_{L} / D\right)\left[X+t_{E}\left(m^{2} B_{E}\left(B_{S}+B_{L}+B_{E}\right)+m B_{E}\right)+t_{W}\left(m ^ { 2 } \left(4 B_{S} B_{E}+3 B_{L} B_{S}\right.\right.\right. \\
& \left.\left.\left.+3 B_{S}^{2}+B_{E}^{2}+B_{L} B_{E}\right)+m\left(9 B_{S}+4 B_{E}\right)+3\right)\right] \\
& Q_{L E}^{*}=\left(B_{E} / D\right)\left[X-t_{E}\left(m^{2}\left(B_{S} B_{E}+2 B_{S} B_{L}+B_{L} B_{E}+B_{S}^{2}+B_{L}^{2}\right)+m\left(4 B_{S}+4 B_{L}\right.\right.\right. \\
& \left.\left.+3 B_{E}\right)+3\right)+t_{W}\left(m^{2}\left(2 B_{S} B_{E}+B_{L} B_{S}+2 B_{S}^{2}-B_{L} B_{E}-B_{L}^{2}\right)\right. \\
& \left.\left.+m\left(5 B_{S}-4 B_{L}\right)\right)\right] \\
& \text { The Nash equilibrium outcomes for the prices are } \\
& P_{S}^{*}=P_{L}^{*}=(1 / 3)\left[X-2 t_{E} m B_{E}+t_{w}\left(3+m B_{E}\right)\right] /\left[\left(m\left(B_{S}+B_{L}+B_{E}\right)+3\right)\right] \\
& P_{E}^{*}=(1 / 3)\left[X+t_{E}\left(6+2 m B_{S}+2 m B_{L}\right)-t_{w}\left(m B_{S}+m B_{L}\right)\right] \\
& /\left[\left(m\left(B_{S}+B_{L}+B_{E}\right)+3\right)\right] .
\end{aligned}
$$

\footnotetext{
${ }^{13}$ The equations were solved using a computer package called Mathcad.
} 


\section{Appendix II: Profit changes with respect to transaction cost changes}

The profit function for the $S$-firm is

$$
\pi_{S}=P_{S} Q_{S S}+P_{L} Q_{S L}+P_{E} Q_{S E}-t_{W} Q_{S L}-t_{E} Q_{S E}-f c-0.5 m\left(Q_{S T}\right)^{2}-a_{m} Q_{S T}
$$

Taking the first derivative of the $S$-firm's profits in equilibrium with respect to $t_{E}$, we get

$$
\begin{gathered}
\frac{d \pi_{S}^{*}}{d t_{E}}=\frac{d P_{S}^{*}}{d t_{E}} Q_{S S}^{*}+P_{S}^{*} \frac{d Q_{S S}^{*}}{d t_{E}}+\frac{d P_{L}^{*}}{d t_{E}} Q_{S L}^{*}+P_{L}^{*} \frac{d Q_{S L}^{*}}{d t_{E}}+\frac{d P_{E}^{*}}{d t_{E}} Q_{S E}^{*}+P_{E}^{*} \frac{d Q_{S E}^{*}}{d t_{E}} \\
-t_{w} \frac{d Q_{S L}^{*}}{d t_{E}}-Q_{S E}^{*}-t_{E} \frac{d Q_{S E}^{*}}{d t_{E}}-m Q_{S T}^{*} \frac{d Q_{S T}^{*}}{d t_{E}}-a_{m} \frac{d Q_{S T}^{*}}{d t_{E}} .
\end{gathered}
$$

Now we can use the fact that $P_{L}^{*}=P_{S}^{*}$ (equation (9)) and $d P_{S}^{*} / d t_{E}=d P_{L}^{*} / d t_{E}$ to simplify equation (A5) and obtain the following:

$$
\begin{aligned}
\frac{d \pi_{S}^{*}}{d t_{E}}= & \frac{d P_{S}^{*}}{d t_{E}}\left(Q_{S S}^{*}+Q_{S L}^{*}\right)+P_{S}^{*}\left(\frac{d Q_{S S}^{*}}{d t_{E}}+\frac{d Q_{S L}^{*}}{d t_{E}}\right) \\
& +\left(\frac{d P_{E}^{*}}{d t_{E}}-1\right) Q_{S E}^{*}+\left(P_{E}^{*}-t_{E}\right) \frac{d Q_{S E}^{*}}{d t_{E}}-t_{w} \frac{d Q_{S L}^{*}}{d t_{E}}-m Q_{S T}^{*} \frac{d Q_{S T}^{*}}{d t_{E}}-a_{m} \frac{d Q_{S T}^{*}}{d t_{E}}
\end{aligned}
$$

By analogy, we can find a similar equation for the change in profits of the $L$-firm with respect to a change in $t_{E}$ :

$$
\begin{aligned}
\frac{d \pi_{L}^{*}}{d t_{E}}= & \frac{d P_{S}^{*}}{d t_{E}}\left(Q_{L S}^{*}+Q_{L L}^{*}\right)+P_{S}^{*}\left(\frac{d Q_{L S}^{*}}{d t_{E}}+\frac{d Q_{L L}^{*}}{d t_{E}}\right) \\
& +\left(\frac{d P_{E}^{*}}{d t_{E}}-1\right) Q_{L E}^{*}+\left(P_{E}^{*}-t_{E}\right) \frac{d Q_{L E}^{*}}{d t_{E}}-t_{w} \frac{d Q_{L S}^{*}}{d t_{E}}-m Q_{L T}^{*} \frac{d Q_{L T}^{*}}{d t_{E}}-a_{m} \frac{d Q_{L T}^{*}}{d t_{E}} .
\end{aligned}
$$

Now we can find the difference between equations (A7) and (A6), and take advantage of

$$
\frac{d Q_{S S}^{*}}{d t_{E}}=\frac{d Q_{L S}^{*}}{d t_{E}}, \frac{d Q_{S L}^{*}}{d t_{E}}=\frac{d Q_{L L}^{*}}{d t_{E}}, \frac{d Q_{S E}^{*}}{d t_{E}}=\frac{d Q_{L E}^{*}}{d t_{E}}, \text { and } \frac{d Q_{S T}^{*}}{d t_{E}}=\frac{d Q_{L T}^{*}}{d t_{E}}
$$


from (11)-(14)) to cancel out or combine some terms. The result is

$$
\begin{aligned}
& \frac{d \pi_{L}^{*}}{d t_{E}}-\frac{d \pi_{S}^{*}}{d t_{E}}=\frac{d P_{S}^{*}}{d t_{E}}\left(Q_{L S}^{*}+Q_{L L}^{*}-Q_{S S}^{*}-Q_{S L}^{*}\right)+\left(\frac{d P_{E}^{*}}{d t_{E}}+1\right)\left(Q_{L E}^{*}-Q_{S E}^{*}\right) \\
& -t_{w}\left(\frac{d Q_{L S}^{*}}{d t_{E}}-\frac{d Q_{S L}^{*}}{d t_{E}}\right)+m\left(Q_{S T}^{*}-Q_{L T}^{*} \frac{d Q_{L T}^{*}}{d t_{E}}\right.
\end{aligned}
$$

which has four terms showing us four different effects of a decrease in $t_{E}$.

The first term, $\left(d P_{S}^{*} / d t_{E}\right)\left(Q_{L S}^{*}+Q_{L L}^{*}-Q_{S S}^{*}-Q_{S L}^{*}\right)$, shows the how the price change within the small and large country markets affects the relative revenues of the two firms. The second term, $\left(d P_{E}^{*} / d t_{E}+1\right)\left(Q_{L E}^{*}-Q_{S E}^{*}\right)$, shows us the change in relative revenues of the two firms on sales to the external country. The third term, $\left(-t_{w}\right)\left(d Q_{L S}^{*} / d t_{E}-d Q_{S L}^{*} / d t_{E}\right)$, shows the change in total transaction costs on trade between the small and large countries for the two firms relative to each other. The fourth term, $m\left(Q_{S T}^{*}-Q_{L T}^{*}\right) d Q_{L T}^{*} / d t_{E}$, takes into account how the cost of production should change for the large firm relative to the small firm.

To aid in clarifying the sign of (A8), we can write

$$
\frac{d P_{C}^{*}}{d t_{E}}=\frac{d\left(a_{d}-\left(1 / B_{C}\right) Q_{T C}^{*}\right)}{d t_{E}}=\frac{-1}{B_{C}}\left(\frac{d Q_{T C}^{*}}{d t_{E}}\right),
$$

so we can replace $\frac{d P_{S}^{*}}{d t_{E}}$ with $\frac{-1}{B_{S}}\left(\frac{d Q_{T S}^{*}}{d t_{E}}\right)$ and $\frac{d P_{E}^{*}}{d t_{E}}$ with, $\frac{-1}{B_{E}}\left(\frac{d Q_{T E}^{*}}{d t_{E}}\right)$ and we can let

$B_{s}=R B_{L}$,

where $0<R<1$. We then obtain

$$
\frac{d \pi_{L}^{*}}{d t_{E}}-\frac{d \pi_{S}^{*}}{d t_{E}}=\frac{(1-R) B_{L} B_{E} m t_{w}\left[(2 / 3)+1 /\left(m B_{E}+(1+R) m B_{L}+1\right)\right]}{\left(m B_{E}+(1+R) m B_{L}+3\right)}
$$

the negative of which is given in equation (17). 